Faculdade de Ciências Econômicas UFRGS

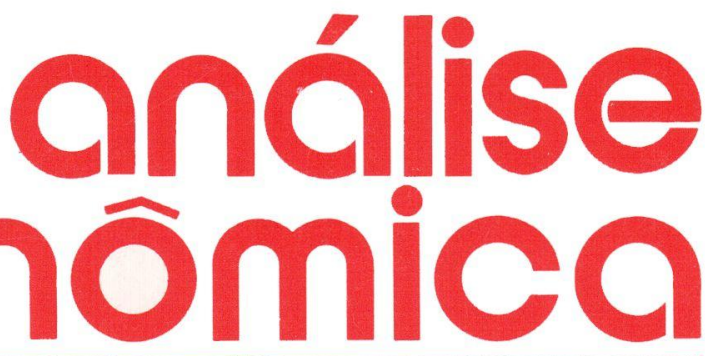

- PROgRAMA dE ESTABILIZAÇÃo DO GOVERNO COLLOR: CENTO E DEZ DIAS DEPOIS

Yeda Rorato Crusius

- SEGURO-DESEMPREGO E SUA INTEGRAÇÃO COM O SISTEMA NACIONAL DE EMPREGO José Paulo Zeetano Chahad

- RENDIMENTOS DECRESCENTES E PREÇO DO CAPITAL

Paolo Sylos Labini

- MARK-UP E DESTRUIÇÃO CRIADORA

Flávio Vasconcellos Comim

- TEORIA MONETÁRIA DE KEYNES Fernando Ferrari Filho

- ESTADO E PEQUENA PRODUÇÃO José Juliano de Carvalho Filho Ana Maria Castelo

- RACIONALIZAÇÃo DA PRODUÇÃo E ENSINO PROFISSIONAL (RS: 1889-1930) Sanara Jatahy Pesavento

- CONTRIBUICÕ̃ES À TEORIA DA LOCALIZAÇÃO INDUSTRIAL

Ruy Aguiar da Silva Leme

- POlaRizaÇÃo E deśolarizaÇÃo INDUSTRIAL NO BRASIL E NO RIO GRANDE DO SUL

Nali de Jesus de Souza
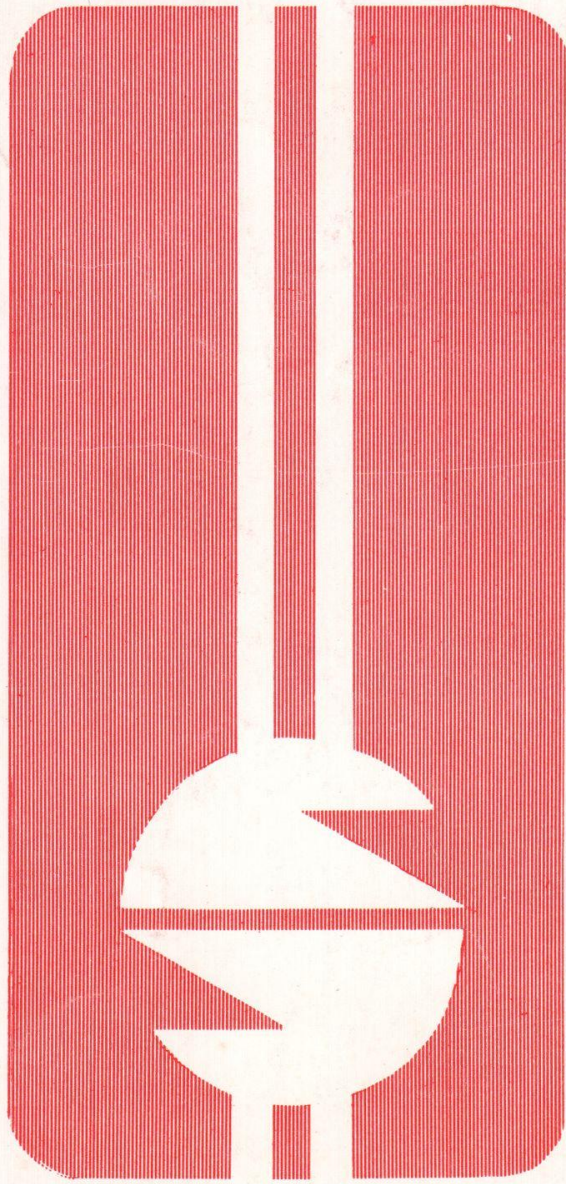
UNIVERSIDADE FEDERAL DO RIO GRANDE DO SUL

Reitor. Prof. Tuiskon Dick

FACULDADE DE CIÊNCIAS ECONÔMICAS

Diretor. Prof. Walter Meucci Nique

CENTRO DE ESTUDOS E PESQUISAS ECONÔMICAS

Diretor: Reinaldo Ignacio Adams

DEPARTAMENTO DE CIÉNCIAS ECONÔMICAS

Chefe: Prof. Pedro Cezar Dutra Fonseca

CURSO DE PÓS-GRADUAÇÃO EM ECONOMIA

Coordenador. Prof. Nali de Jesus de Souza

CURSO DE PÓS-GRADUAÇĀO EM ECONOMIA RURAL

Coordenador. Prof. Atos Freitas Grawunder

CONSELHO EDITORIAL: Achyles Barcelos da Costa, Aray Miguel Feldens, Atos Freitas Grawunder, Carlos Augusto Crusius, Ernani Hickmann, João Rogério Sanson, Juvir Luiz Mattuella, Maria Imilda da Costa e Silva, Nali de Jesus de Souza, Nuno Renan Lopes de Figueiredo Pinto, Otília Beatriz Kroeff Carrion, Otto Guilherme Konzen, Paulo Alexandre Spohr, Pedro Cezar Dutra Fonseca, Reinaldo Ignacio Adams, Roberto Camps Moraes, Valter José Stülp, Yeda Rorato Crusius, David Garlow (Wharton Econometrics Forecasts Association, E.U.A.), Edgar Augusto Lanzer (UFSC), Eleutério F.S. Prado (USP), Fernando Holanda Barbosa (FGV/RJ), Gustavo Franco (PUC/RJ), Joaquim Pinto de Andrade (UnB), Juan H. Moldau (USP), Werner Baer (Univ. de Illinois, E.U.A.).

COMISSÃO EDITORIAL: Atos Freitas Grawunder, Pedro Cezar Dutra Fonseca, Reinaldo Ignacio Adams e Roberto Camps Moraes.

EDITOR: Nali de Jesus de Souza.

SECRETARIA: Maria Ivone de Mello (normalização), Vanete Ricacheski (revisão de textos), Zélide Bregalda (Secretária).

FUNDADOR: Prot. Antônio Carlos Santos Rosa.

Os materiais publicados na revista Análise Econômica são de exclusiva responsabilidade dos autores. É permitida a reprodução total ou parcial dos trabalhos, desde que seja citada a fonte.

Aceita-se permuta com revistas congêneres. Aceitam-se, também, livros para elaboração de resenhas ou recensões.

Toda correspondência, material para publicação, assinaturas e permutas devem ser cirigidos ao seguinte destinatário:

PROF. NALI DE JESUS DE SOUZA

Revista Análise Econômica

Av. João Pessoa, 52

90.040 - PORTO ALEGRE (RS), BRASIL

Telefone: 25-58-44 ramal 33 


\title{
A AÇÃO DO ESTADO \\ E AS POSSIBILIDADES \\ DA PEQUENA PRODUÇÃO*
}

\author{
José Juliano de Carvalho Filho ${ }^{\star \star}$ \\ Ana Maria Castelo ${ }^{\star \star \star}$
}

\section{INTRODUÇÃO}

Este trabalho tem como objetivo analisar a situação dos pequenos produtores no que diz respeito à ação governamental e oportunidades de acesso à terra.

A década de 70 assistiu a uma rápida modernização do setor agrícola brasileiro alicerçada em algumas políticas básicas como a do crédito rural subsidiado, a de preços mínimos e a de assistência técnica.

A despeito da não implementação de políticas de caráter mais estrutural, a mudança na base técnica ocorreu e imprimiu grandes alteraçōes no meio rural, destacando-se uma nova composição de classes sociais ${ }^{1}$. Nestas circunstâncias, a modernização revestiu-se de um caráter bastante conservador, pois orientou-se basicamente para médios e grandes produtores.

Os resultados desse processo refletiram-se nos dados dos censos demográficos e agropecuários de 1980 que registraram crescimento do éxodo rural, do assalariamento e, principalmente, dos niveis de concentração da renda e da posse da terra.

Já a década de 80 toi marcada por alguns eventos importantes

* Trabalho apresentado no XVII ENCONTRO NACIONAL DE ECONOMIA, 17. Fortaleza, dez., 1989.

** Protessor da Fea-IPE-USP.

*** Mestre em Economia pelo IPE-USP.

1 As transformações resultantes do processo de modernização têm sido discutidas por diversos autores como Wilkinson, Muller, Sorj e Graziano, entre outros.

\begin{tabular}{|l|l|l|l|l|}
\hline ANÁLISE ECONÔMICA & ANO 8 & No13 & MARÇO/90 & p.133-144 \\
\hline
\end{tabular}


como a recessão de $81 / 83$, uma grande seca no Nordeste e, finalmente, a maior abertura política que permitiu a retomada de algumas questōes importantes; entre as quais destaca-se a possibilidade de acesso à terra de enorme contingente de produtores e trabalhadores marginalizados do processo de modernização.

Tais eventos, sem dúvida, tiveram reflexo sobre a estrutura de produção agropecuária e imprimiram algumas mudanças importantes, embora ainda não se possa avaliar se definitivas ou não.

Entre as alterações mais importantes verificou-se que o número de estabelecimentos cresceu de forma mais intensa que a área total, provocando queda na área dos estabelecimentos. Houve uma tendência à estabilização no nivel de tecnificação com manutenção das desigualdades inter-regionais e, finalmente, observou-se um crescimento da importância dos pequenos produtores, em função do aumento no número de pequenos estabelecimentos e do pessoal ocupado por eles.

O crescimento da pequena produção, de certa forma, surpreendeu àqueles que acreditaram no progressivo desaparecimento deste segmento social.

Neste sentido, tal resultado nos remete à "velha" discussão que permeia as análises sobre a modernização do setor agrícola: se o tamanho do estabelecimento pode ser obstáculo a sua modernização e, nesse caso, se haveria uma tendência a eliminação da pequena produção.

Alguns autores ${ }^{2}$ detectaram uma transformação dinâmica desse segmento, no qual a tecnificação passou a ser o elemento determinante da integração da pequena produção com o setor modernizado da economia. No entanto, a tecnificação atingiu uma camada reduzida dos pequenos produtores e uma parcela significativa permaneceu alijada do processo, o que, se não provocou sua eliminação através da proletarização, conduziu a uma piora nos seus niveis de vida.

Nesse caso, embora a modernização não fosse orientada no sentido de eliminar a pequena produção, isto ocorreu em diversas circunstâncias e, principalmente, determinou uma transformação diferenciada dos pequenos produtores.

A existência de um segmento marginalizado com baixos niveis de renda, um padrão de vida bastante precário e com acesso à terra bastante reduzido determinou, a partir de meados da década de 70, a criação de programas orientados para esse público-meta. Tais programas tinham subjacentes aos objetivos de elevar os niveis de renda e de vida

2 Como por exemplo, Sorj (1980) e Silva (1985). 
desses pequenos produtores, a idéia de integrá-los ao mercado, modernizando-os; e pretendiam dessa forma ser uma alternativa à realização de mudanças mais estruturais como uma Reforma Agrária. Entre os principais programas criados nesse período estão ${ }^{3}$ o Programa de Redistribuição de Terras e de Estímulo à Agroindústria (PROTERRA); Programa Plurianual de Irrigação; Programa de Desenvolvimento de Áreas Integradas do Nordeste (POLONORDESTE); Programa Especial de Transformação e Fortalecimento da Economia da Região Semi-Árida do Nordeste (Projeto Sertanejo); e o Programa de Desenvolvimento Integrado do Noroeste do Brasil (POLONOROESTE).

Já na década de 80 foram criados o Programa de Apoio ao Pequeno Produtor (PAPP). Programa de Apoio a Organização de Pequenos Produtores Rurais do Nordeste (São Vicente), o Programa Nacional de Irrigação (PRONI) e o Programa Nacional de Reforma Agrária (PNRA).

Apesar da multiplicidade de programas, quase nada se conseguiu no sentico de reduzir a extrema pobreza de grande número de pequenos produtores, prevalecente no meio rural brasileiro.

Diversas avaliaçōes ${ }^{4}$ realizadas indicaram distorções nos objetivos e/ou na execuções dos planos que contribuíram para diluir de forma dramática o impacto esperado. Alguns dos problemas observados e que permearam quase todos programas foram (Carvalho Filho, 1988):

i) contradição de açōes do Estado através de programas de natureza distintas em uma mesma área;

ii) elevado grau de ineficiência no cumprimento das metas dos segmentos sociais em contraposição a uma eficiência razoável no cumprımento das metas dos segmentos da infra-estrutura; o segmento fundiário, em particular, apresentou, de modo geral, um desempenho próximo do nulo ${ }^{5}$, mesmo o Polonordeste que em sua segunda fase admite a importância de uma política de acesso à terra para pequenos produtores, não consegulu implementar uma política fundiária de

${ }^{3}$ Cabe observar que a quase totalidade dos programas está nas regióes Nordeste e Norte do pais, onde se situa a maior parcela dos pequenos produtores pauperizados. Esse direcionamento espacial reflete a desigualdade da modernização que beneficiou principalmente o Centro-sul do pals.

${ }^{4}$ As avaliações referem-se aos programas mais antigos implementados na década de 70.

5 Em relação à questāo fundiária, cabe chamar atenção que os programas especiais já foram criados pelas autoridades governamentais, como uma alternativa à realização de uma reforma agrária mais ampla. A intenção êra, através de programas realizados, resolver o problema fundiário em áreas específicas. 
minimo impacto;

iii) a seletividade caracterizou muitos dos segmentos dos programas como, por exemplo, o de crédito rural que, em geral, se orientou para um pequeno grupo de produtores, alguns dos quais nem sequer fazlam parte do grupo-meta;

iv) falta de integração das diversas ações e projetos, e deficiências graves quanto aos aspectos administrativos e institucionais;

v) apropriação dos benefícios por poucos produtores o que contribuiu

- para aprofundar as desigualdades existentes;

vi) não se conseguiu uma melhoria no nivel de renda e no padrão de vida das populaçōes locais.

A constatação dos problemas acima gerou uma série de pressōes da sociedade como um todo e, em especial, dos organismos internacionais de financiamento, no sentido de revisar os programas especiais e criar uma política fundiária de natureza ampla e consistente. Dessa forma, o segmento fundiário transformou-se no "carro-chefe" do Programa de Apoio ao Pequeno Produtor (PAPP), criado em substituição aos demais programas especiais da região Nordeste. No âmbito nacional, decidiu-se também pela necessidade de uma ampla reforma agrária, que se consubstanciaria na implementação do Plano Nacional de Reforma Agrária (PNRA).

Diante desse quadro e considerando o grande acréscimo de pequenos estabelecimentos no periodo $80 / 85$, pergunta-se se estaria havendo no país uma ampliação das oportunidades de acesso à terra para pequenos produtores.

Frente à perspectiva de melhoria nas condiçōes de reprodução da pequena produção, o objetivo desta seção é realizar um estudo de suas oportunidades de acesso à terra, avaliando seu desempenho recente (anos 80 ) e com especial atenção aos programas de desenvolvimento rural.

\section{FORMAS DE ACESSO À TERRA E A IMPORTÂNCIA dOS PROGRAMAS DE DESENVOLVIMENTO RURAL.}

Segundo Barbosa (1987), as principais formas de acesso à terra são:

- a sucessão hereditária; 
- usucapião especial;

- o apossamento de terras públicas;

- os projetos de colonização;

- os programas especiais;

- os programas de Reforma Agrária;

- as operações de compra e venda no mercado;

- os contratos de parceria e arrendamento.

Barbosa observa que a sucessão hereditária pode ter uma influência positiva na desconcentração na medida em que provoca a divisão de grandes estabelecimentos; por outro lado, ela também contribui para o crescimento dos minifúndios ao provocar uma divisão excessiva dos pequenos estabelecimentos. No entanto, a sucessiva divisão dos grandes estabelecimentos não é muito comum e, em geral, juntam-se os estabelecimentos através de compra ou qualquer outro acordo. Já a divisão dos pequenos estabelecimentos é mais provável. Em última instância, porém, a herança beneficia apenas as famílias já com sua posse.

O Usucapião Especial foi regulamentado a partir da Lei $n=6.969$ de dezembro de 1981 segundo o qual "todo aquele que não sendo proprietário rural nem urbano, possuir como sua, por 5 anos ininterruptos, sem oposição, área rural contínua, não excedente a 25 ha e a houver tornado produtiva com seu trabalho e nela tiver morada, adquirir-lhe-á o domínio independente de justo título e boa fé; podendo requerer ao juiz que assim o declare por sentença, a qual servirá de título para transcrição no Registro de Imóveis". A lei determina ainda que na ação será adotado procedimento sumaríssimo assegurạda a preferência à sua instrução e julgamento. Ele pode ser requerido tanto em áreas particulares quanto em terras devolutas.

Por ocasião em que foi sancionada, a lei do usucapião criou a expectativa de que seria aplicada em grande escala. No entanto, isto năo se confirmou em função da dificuldade do pequeno posseiro comprovar a posse mansa e ainda pela falta de apoio juridico. Não há dados disponiveis sobre sua aplicação.

Barbosa destaca o apossamento de terras públicas como uma das formas de acesso à terra mais democrática que pode abrir oportunidades para um grande contigente de "Sem-Terras". Na década de 70, o apossamento das terras públicas, na amazônia, por pequenos produtores chegou a ser bastante incentivado pelas autoridades governamentais. Via-se aí uma solução "fácil"' para dois problemas; a integração da amazônia e a existência de um grande número de pequenos produtores 
sem terra. Em primeiro momento, tais produtores puderam se apossar de uma porção de terra "sem grandes dificuldades", isto é, após abrir caminho em meio a floresta, locais de dificil acesso e sem qualquer infra-estrutura. No entanto, na medida em que se despertou o interresse de grandes produtores e grupos industriais, a politica foi revertida em favor desses grandes produtores e surgiram muito conflitos culminando com a expulsão violenta ou não dos pequenos posseiros.

Atualmente, 0 apossamento das terras públicas vai se tornando inviável em função da sua localização em áreas cada vez mais inacessiveis, ou seja, do próprio esgotamento da fronteira e também em decorrência da ação violenta dos "grileiros" expulsando os pequenos posseiros.

O número de mortes resultante desses conflitos, como é sabido, tem crescido significativamente nos últimos anos.

É relevante notar que ainda existem terras públicas nas regiōes de ocupação antiga. No Nordeste, em especial, observou-se no período 80/85, uma ação concentrada por parte das autoridades governamentais, no sentido de regularizar tais ocupaçóes (essas ações vieram no bojo do segmento fundiário dos programas especiais). Barbosa levanta a possibilidade do maior crescimento dos pequenos estabelecimentos estar diretamente relacionada a essas ações. Por outro lado, ele verifica a progressiva ineficiência do acesso à terra pelo apossamento em decorrência da lentidão com que o poder público tem procedido à discriminação, à arrecadação antecipada e à regularização das posses nas terras devolutas federais e estaduais.

Tal ineficiência tem contribuido para o aumento das ocupaçōes que passam a ocorrer até como forma de pressionar o governo a agilizar as açōes necessárias.

A colonização oficial tem igualmente se concentrado em áreas com fronteiras externas e, particularmente, na Região Norte. Tradicionalmente, ela também tem se configurado, a secessivos governos, como uma alternativa à realização de uma reforma agrária.

Apesar da pretensa idéia de substituir a reforma por projetos de colonização, eles nunca foram em grande número e quase sempre apresentaram muitos problemas. A tabela 01 a seguir mostra que, desde a implementação dos primeiros projetos até 1988 , foram assentadas apenas 145.622 famílias.

As avaliações realizadas por Carvalho Filho (1988) para o Projeto de Colonização de Novas Áreas, em Rondônia, refletem, de modo geral, 


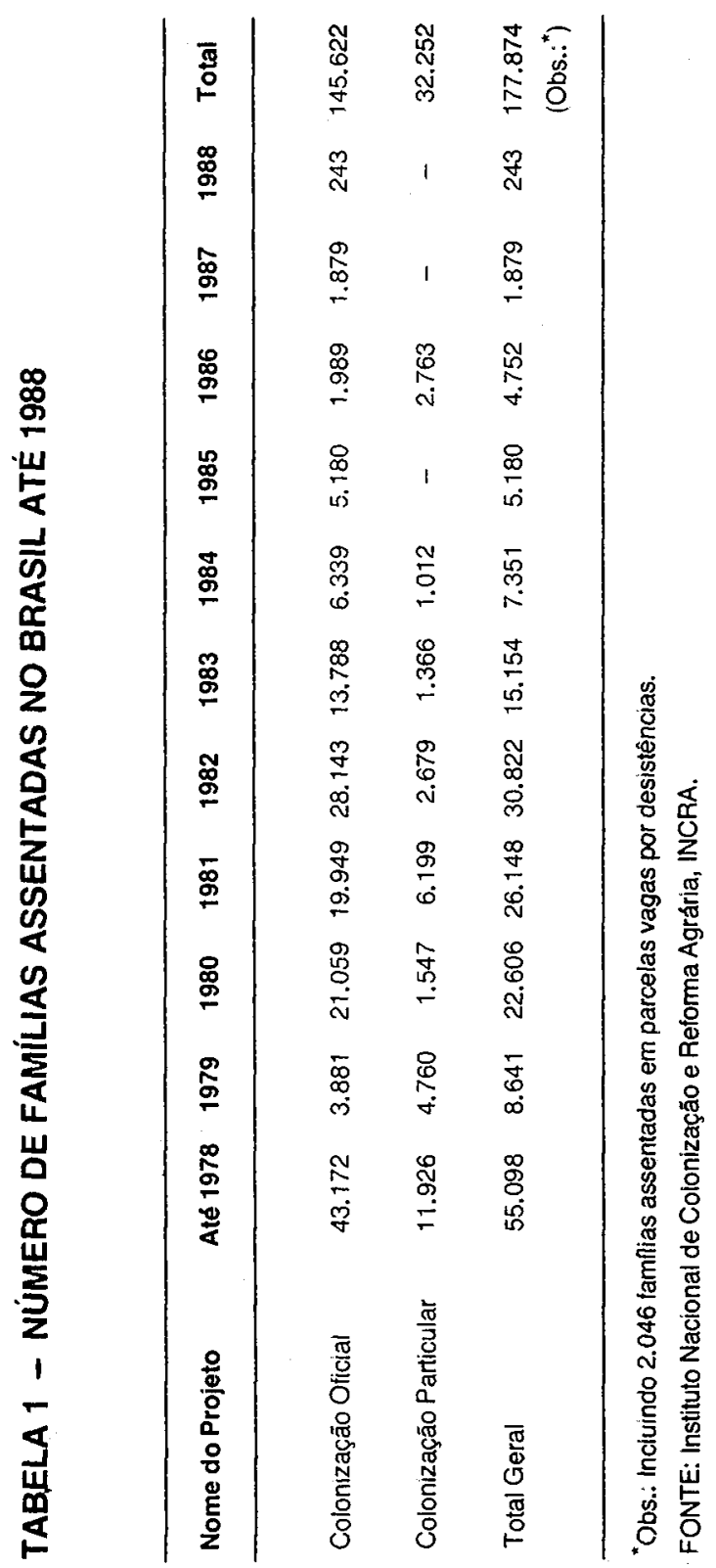


os problemas detectados em várıs outros. Nesse projeto, evidenciou-se que sua capacidade de assentamento foi muito inferior às necessidades da região; os projetos implantados apresentaram deficiências em qualidade do solo, nos serviços de apoio e nos componentes sociais; verificounse ainda uma alta rotatividade dos ocupantes dos lotes.

Outro fator a desestimular a política de colonização é o seu alto custo. Informações do Banco Mundial que financia alguns projetos em Rondônia indicam um custo total por família da ordem de US $\$ 17.180$ (Barbosa, 1987).

Nestas circunstâncias, os projetos terminam por reproduzir grande parte dos problemas enfrentados pelos pequenos produtores fora deles, levando muitos colonos a comercializarem seus lotes. Há dados de que, em Rondônia, 20 a $40 \%$ dos lotes são comercializados pelos colonos originais (Barbosa, 1987).

Tal quadro por si só indica que a colonização oficial não se configura em uma forma fácil de acesso à terra e tem sido mais restrita a partir de 1985 quando o governo federal praticamente desativou a abertura de novos projetos.

Os programas especiais, como já mencionado antes, trouxeram consigo a perspectiva de melhoria de vida dos pequenos produtores e trabalhadores sem terra. Como os primeiros programas se distanciaram bastante de seus objetivos, os que foram criados na década de 80 , particularmente, o Programa Nacional de Irrigação (PRONI) e o Programa de Apoio ao Pequeno Produtor (PAPP) procuraram enfatizar as ações voltadas para facilitar o acesso à terra para os pequenos produtores.

Se, por um lado, o PRONI foi concebido dentro de uma linha de preocupação que procurava facilitar o acesso à terra, por outro lado, os pesados investimentos necessários à irrigação, fizeram com que em sua implernentação, o Programa desse ênfase maior à irrigação privada envolvendo médios e grandes produtores (Barbosa, 1987).

O desvio do programa torna-se mais patente face aos resultados do relatório da avaliação do programa na Região Nordeste (PROINE) (Silva, 1988). De acordo com o relatório, devido às desapropriações e/ou desapossamentos necessários para realização das obras de irrigação, houve um "deslocamento de grande contingente populacional que perdeu - de forma muito rápida - os seus meios tradicionais de sobrevivência". Esse quadro é agravado pelo fato de poucas vezes o valor das desapropriações foi suficiente para aquisição de um novo lote cultivável. Dessa forma, conclui-se que o Programa de Irrigação tem agido em sen- 
tido contrário ao pretendido com um efeito perverso sobre seu públicometa.

Entre os programas especiais da década de 80, o Programa de Apoio ao Pequeno Produtor (PAPP) foi o que gerou a maior expectativa de mudança em uma política que, tradicionalmente, vinha marginalizando o pequeno produtor.

A partir dos erros do passado, o programa procurou inovar, de forma a, efetivamente, beneficiar seu público-meta.

Dessa forma, o PAPP se distingue dos anteriores em dois aspectos principais: na diminuição do número de segmentos do programa e na centralização de suas ações em torno do segmento fundiário. Com a redução no número de segmentos, pretendia-se solucionar o problema de coordenação e integração interinstitucional resultante do envolvimento de uma quantidade excessiva de instituições de natureza distintas. A atuação dos demais componentes, em torno do segmento fundiário, objetiva concentrar as ações nas áreas beneficiadas pelo segmento fundiário, aumentando assim, a sua eficácia.

Algumas avaliações parciais já realizadas (Carvalho Filho e Castelo, 1989) têm indicado que persistem os problemas relativos à falta de coordenação e integração interinstitucional, apesar do menor número de componentes. No entanto, o problema mais grave que as avaliações têm ressaltado é a progressiva diluição das metas fundiárias e a conseqüente desvinculação entre os demais componentes e ação fundiária. Desde sua elaboração, o PAPP tem sido objeto de pressões em vários sentidos, que se consubstanciam na mudança de ênfase na necessidade de uma ampla reestruturação fundiária no Nordeste (Castelo, 1985).

O Progressivo redirecionamento do segmento fundiário do PAPP está diretamente associado ao esvaziamento que se verificou na proposta de realização de uma reforma agrária no país.

Assim como o PAPP, a Reforma Agrária foi sendo redimensionada e restringida diversas vezes, tendo seu espaço gradativamente reduzido (Carvalho Filho, 1989).

Deve-se chamar atenção para a existência de outros programas especiais na região Nordeste como, por exemplo, o São Vicente e o Padre Cícero. Estes programas também são orientados especialmente para o pequeno produtor, mas têm ùma abrangência menor em relação aos seus componentes, podendo, portanto, serem visto mais como programas complementares aos anteriores. O Padre Cícero, particularmen- 
te, se configura mais como um subprojeto do PAPP, tendo parte de seus recursos origem no próprio PAPP. De qualquer forma, năo se dispõe de informações de natureza avalıativa sobre esses programas.

Se os programas governamentais não são suficientemente amplos e profundos para melhorar de forma mais significativa o quadro de opções de acesso à terra do pequeno produtor, existem duas outras formas, às quais, eventualmente, ele pode recorrer: o acesso via compra e venda e face às limitaçōes da propriedade direta da terra, o recurso ao acesso indireto, a parceria e o arrendamento.

$O$ acesso à compra e venda, na medida em que implica um grande envolvimento econômico de um produtor cujos recursos estão na maior parte dos casos destinades à auto-reproduçāo, torna-se inviável.

Como inviabilizadores desse acesso, Barbosa relaciona as seguintes causas (Barbosa, 1987):

i) a política pública via incentivos, subsidios e investimentos diretos, tende a estimular a concentração e não o fracionamento de grandes parcelas;

ii) ineficiência do instrumento da taxaçãa territorial rural que, efetivamente, deveria penalizar os grandes imóveis que são mantidos sem uso ou parcialmente ociosos;

iii) inexistência do crédito fundiário como linha permanente e usual, com termos e condições compativeis com o baixo nivel de poupança dos pequenos produtores;

iv) a inflação crônica transforma a terra em ativo preferencial para a manutenção do valor aquisitivo da moeda, desestimulando a venda e/ou fracionamento dos imóveis, ainda não utilizados;

v) inexistência de uma politica agrícola especialmente orientada para o segmento camponês.

Por fim, resta ao pequeno produtor o acesso temporário à terra. Os dados da Sinopse preliminar do Censo de 1985 mostraram um crescimento da parceria em todas as regiōes do pais. Todavia, as informações atuais mostram a generalização do assalariamento.

Já o arrendamento por exigir uma combinação prévia de uma taxa ou renda fixa se configura em negócio mais arriscado para pequenos produtores de culturas e técnicas tradicionais.

Neste sentido, o crescimento do arrendamerito tem-se dado nas regiōes mais modernizadas como Sudeste, Sul e Centro-Oeste.

Em teoria, não deveria haver muitos problemas com o acesso temporário à terra, mas, na prática, em decorrência do descumprimento 
à lei (o Estátuto aa Terra) que èstabelece niveis máximos à renda paga pelo prooutơr ao proprietárió, è pouer da influência dèste último é muito grande, principalmente no caso da parceria. Nestè sentido, a subordinação do pequeno produtor tradicional ao proprietário faz com que a parceria dificilmente posśbilitite uma melhoria ể seu padrão de vida e mujto menos a aquisição de sua própria terra.

\section{CONCLUSÕES E PERSPECTIVAS}

Nã̃o houve ampliação significativa das oportunidades de acesso à terra para pequenos prodútores. Essa é a conclusão definitiva que a análise de todas opções disponiveis permite tirar.

A política fundiária realizada pelo poder público nos anos 80 avança em relação ao periodo anterior na medida em que os novos programas orientados para o pequeno produtor deram mais ênfase à questão fundiária.

Dessa forma, cabe lembrar que houve um crescimento significativo no númeto de assentámentos localizados principalmente na Região Nordeste. No entanto, a implementação dos novos assentamentos ainda foi bastante tímida face à dimensão do problema fundiário e tem apresentado uma série de distorções (Castro, 1988). Assim como nos projetos de cơlonização, muitos dos assentamentos terminam por reprocuzir internamente a tendência das relaçōes existentes fora deles. Nesse contexto, o quadro que se pøde vislumbrar ainda é de um sensivel atraso no segmento fundiário, principalmente quando se considera que a aquisiçāo de terras mediante desapropriação ou compra continuou restrita à algumas áreas ou vindo como solução ao agravamento de conflitos.

Os mercados de parceria e arrendamento, de modo geral, são bastante informais e desfavorávéis aos pequenos produtores. $O$ acesso mediante a compra é praticamente inviável.

Nëstas circunstâncias, o pequeno produtor tem muito poucas chances de conseguir suă terra por esforço próprio, principalmente quando se leva em consideração o esgotamento da fronteira externa, 0 que o torna cada vez mais dependente da açâa direta do governo, ou seja, dos Prógramas de Desenvolvimento Rural. No entanto, mesmo esta alternativa deve-se restringir significativamente ante a implementação da "Operação Desmonte" pelo Governo Federal. Poucos estados nordestinos teriam condições de arcar com a contrapartida de recursos na- 
cionais exigida pelo Banco Mundial.

Diante deste quadro, as perspectivas para a pequena produção vão depender essencialmente da correlação de forças prevalecentes na sociedade brasileira, a qual decidirá sobre a criação ou não de alternativas para este segmento social.

\section{BIBLIOGRAFIA}

BARBOSA, T. O Mercado de Terras no Brasil e os Pequenos Produtores. Brasília, 1987. Mimeo.

CARVALHO FILHO, J. J. de. Ação do Estado no Meio Rural do Nordeste e Noroeste: Uma Discussão Sobre Eficácia. Anais do XXVI Congresso Brasileiro de Economia e Sociologia Rural. Fortaleza - 01 a 05 de agosto de 1988.

CARVALHO FILHO, J. J. Política Fundiária, um Balanço. São Paulo, Boletim de Informações FIPE, n. 110, jul. 1989.

CARVAlHo FILHO, J. J. \& CASTELO, A. M. Posse e Uso da Terra no Brasil. São Paulo, IPE/USP, 1989. (Trabalho não Publicado).

CASTELO, A. M. Desenvolvimento Rural Integrado e a Pequena Produção: Caso da Serra de Ibiapaba. São Paulo, IPE/USP, 1985. (Dissertação de Mestrado em Economia). Mimeo.

CASTRO, M. H. M. et alii Reforma Agrária: um Estudo Preliminar. Revista da Associação Brasileira de Reforma Agrária. 18(1): 5-35, abril/junho, 1988.

SILVA, J. G. Tecnologia e Campesinato: o Caso Brasileiro. Revista de Economia Política, 3(4): 21-55, out./dez., 1985.

SILVA, J. G. (Coord.). Estudo Setorial Sobre a Implantação Projetos de Irrigação no Âmbito do PROINE e a Problemática Fundiária do Nordeste - Relatório Sintese. Campinas, Instituto de Economia, UNICAMP, 1988.

SORJ, B. Estado e Classes Sociais na Agricultura Brasileira. Rio de Janeiro, Zahar, 1980. 